Rick A. Relyea · Kerry L. Yurewicz

\title{
Predicting community outcomes from pairwise interactions: integrating density- and trait-mediated effects
}

Received: 4 June 2001 / Accepted: 14 February 2002 / Published online: 13 April 2002

(C) Springer-Verlag 2002

\begin{abstract}
Understanding how species interactions shape the structure of ecological communities based on pairwise comparisons has been a difficult undertaking for ecologists because effects in reassembled communities can be different than simple density-mediated interactions would suggest. Part of this complexity occurs because many species change their behavior and morphology with different predators and competitors and, thus, change their per-capita interaction rates (i.e. trait-mediated interactions). Our objective was to use a simple experimental community of two predators (larval dragonflies, Anax longipes, and larval salamanders, Ambystoma tigrinum), two prey (larval green frogs, Rana clamitans, and larval bullfrogs, $R_{.}$catesbeiana), and a shared prey resource to determine whether we can predict interactions in a reassembled community by combining our knowledge of density- and trait-mediated interactions,. We combined pairwise laboratory experiments on predation rates and predator-induced behaviors with a mesocosm experiment to examine density- and trait-mediated effects. We used a factorial combination of no predators, caged Anax (to induce anti-predator traits without changing prey density), and lethal Anax crossed with no predators, caged Ambystoma, and lethal Ambystoma. The species interactions in the reassembled community were qualitatively predictable based on the pairwise experiments. Lethal Anax preyed upon Ambystoma and green frogs while lethal Ambystoma only preyed upon green frogs. Anax also reduced the activity of the green frogs; this caused a decrease in salamander predation on green frogs, a decrease in green frog acquisition of resources, and an increase in bullfrog acquisition of resources. Ambystoma had no effect on green frog activity, no effect
\end{abstract}

R.A. Relyea ( $) \cdot$ K.L. Yurewicz

Department of Biology, University of Michigan, Ann Arbor,

MI 48109, USA

e-mail: relyea+@ pitt.edu

Tel.: +1-412-6244656, Fax: +1-412-6244759

Present address:

R.A. Relyea, Department of Biological Sciences,

University of Pittsburgh, Pittsburgh, PA 15260, USA on resource acquisition by green frogs, and no effect on resource acquisition by bullfrogs. These results suggest that we can better understand how species interact in natural communities if we have a more detailed understanding of trait-mediated mechanisms. However, if predicting the structure of large communities requires identifying how each species alters its traits in the presence of all other species along with altering density, improving our predictive ability may be a prohibitively large undertaking.

Keywords Amphibians - Community ecology . Larval anurans · Phenotypic plasticity .

Trait-mediated interactions .

\section{Introduction}

One challenge for ecologists is to understand how species interactions shape the structure of ecological communities. This has been a daunting task for several decades as ecologists attempted to predict the outcome of species interactions in a community based upon experimental manipulations of species pairs (see reviews by Werner 1992; Adler and Morris 1994; Wootton 1994; Abrams 1995). Typically, investigators have found that communitylevel outcomes are not predictable from adding up pairwise interactions. Often, pairwise interactions are multiplicative (Sih et al. 1998), leading to the conclusion that communities are both unpredictable and complex (Wilbur and Fauth 1990; Werner 1992). A primary reason for this complexity is that early studies focused on documenting how each species in the community affected the density of the other species in the community either through direct interactions or density-mediated indirect interactions. However, many traits are phenotypically plastic (including behavior, morphology, and life history; Lima and Dill 1990; Karban and Baldwin 1997; Kats and Dill 1998; Tollrian and Harvell 1999) and these trait changes can alter the outcome of species interactions (Turner and Mittlebach 1990; Werner and 
Anholt 1996; Beckerman et al 1997; Soluk and Richardson 1997; Relyea 2000). In this case, the strength of species interactions depends upon the ecological context in which the species pair is embedded. These effects have been termed "trait-mediated interactions" (Abrams 1995; also termed "high-order interactions" or "interaction modifications").

Although much more empirical work is required before any generalities can be made, trait-mediated interactions appear to be common in ecological communities. Recent work has focused on the role that predators and competitors play in altering a target species' behavior or morphology and how these trait changes alter the growth and survival of other species in the community (Wissinger and McGrady 1993; McIntosh and Townsend 1996; Beckerman et al. 1997; Peacor and Werner 2000; Relyea 2000). The consensus from these studies is that traitmediated effects can have profound effects on interspecific interactions. Thus, some of the complexity observed in earlier studies that prevented predictions of community structure based on pairwise density-mediated effects might be clarified if we simultaneously consider traitmediated interactions.

Many studies of trait-mediated interactions involve either a single predator or a single prey species (Lima and Dill 1990; Tollrian and Harvell 1999). However, because most communities are composed of multiple predators and multiple prey, we need to expand our empirical studies to larger food webs to obtain a more realistic picture of interaction complexity. However, simply documenting the presence of trait-mediated interactions is no longer the challenge; the existence of trait-mediated interactions is now rarely debated. The challenge is to determine how different environments change an individual's traits, how altered traits change individual performance, and how changes in individual performance translate into changes in interspecific interactions (Worthen and Moore 1991; Wootton 1992; Schmitz 1998; Peacor and Werner 2000).

Our objective was to examine the importance of trait-mediated effects in altering interspecific interactions in pond communities containing larval anurans. This work draws upon a great deal of past research that we and others have conducted on trait- and density-mediated interactions (Werner and Anholt 1996; Peacor and Werner 1997; Van Buskirk and Yurewicz 1998; Relyea and Werner 1999; Relyea 2000, 2001a, b; Yurewicz, unpublished data). Much of this work has tested for trait-mediated effects using predatory dragonfly larvae (Anax junius, A. longipes, Tramea sp.) because dragonflies are abundant and easy to experimentally manipulate. While dragonflies have provided a great deal of insight into predator-prey interactions, it is important that we begin to incorporate other predators, alone and in combination, because predators have the potential to interact with the prey and with each other (Polis et al. 1989; Polis and Holt 1992; Wissinger and McGrady 1993; Soluk and Richardson 1997; Eklöv and Werner 2000).
Study system

Larval anurans have been an excellent study system for ecological investigations for nearly a century (Adolph 1931; Martof 1956; Wilbur 1972; Morin 1983; Werner and McPeek 1994). In North America, tadpoles coexist with diverse predator assemblages (Collins and Wilbur 1979; Dale et al. 1985; Skelly et al. 1999; Relyea 2001b) that can reduce prey density and have a positive indirect effect on the prey's resources (a density-mediated indirect effect; Wilbur 1988; Van Buskirk and Yurewicz 1998; Relyea 2002b). Predators also emit chemical cues (Petranka et al. 1987; Kats et al. 1988) that induce adaptive changes in tadpole behavior, morphology, and life history (Hews 1988; Lawler 1989; McCollum and Van Buskirk 1996; Relyea and Werner 1999). These predator-induced trait changes can alter interaction rates between prey and predators and between prey and resources (Werner and Arnolt1996; Peacor and Werner 1997; Relyea 2000).

We focused on two species of larval anurans (newly hatched green frog tadpoles and second-year bullfrog tadpoles) and two species of predators (larval dragonflies, Anax spp., and larval tiger salamanders, Ambystoma tigrinum) that naturally coexist. We chose these particular species and size classes of tadpoles because they compete for periphyton (Werner and Anholt 1996; Peacor and Werner 1997; Relyea and Werner 1999), but only the green frogs are susceptible to predation. Second-year bullfrogs are large and invulnerable to predators (Relyea and Yurewicz, personal observations). Thus, any changes in bullfrog growth would be due to density- or traitmediated effects of green frogs on the shared resource; in short, the bullfrogs served as a biometer of indirect effects transmitted through a shared resource (Fig. 1). Ambystoma and Anax both kill green frog tadpoles, although predation by Ambystoma is higher (based on laboratory experiments; Relyea 2001b). In contrast, only Anax causes significant reductions in green frog activity (Werner 1991; Relyea 2001a). Based on laboratory experiments, both predators should have little effect on green frog morphology (Relyea 2001a). Anax and Ambystoma also have the potential to kill each other and affect each other's behavior. Anax can kill Ambystoma of similar size but, because of gape limitations, it was unlikely that Ambystoma could consume Anax of similar size (K. L. Yurewicz, personal observations). Whether the predators could affect each other's behavior was unknown. In summary, we manipulated two components of a five-component system that contained numerous potential density-mediated and traitmediated effects (Fig. 1).

Based on the above food web and our knowledge of trait changes in laboratory experiments, we manipulated the presence and absence of caged and lethal predators and predicted the effects on the growth and survival of green frogs and bullfrogs. We had a number of hypotheses: (1) neither predator should affect green frog morphology; (2) Ambystoma should kill more green frogs than Anax; (3) because only Anax reduces green frog activity, adding caged Anax should decrease the predation rate of 


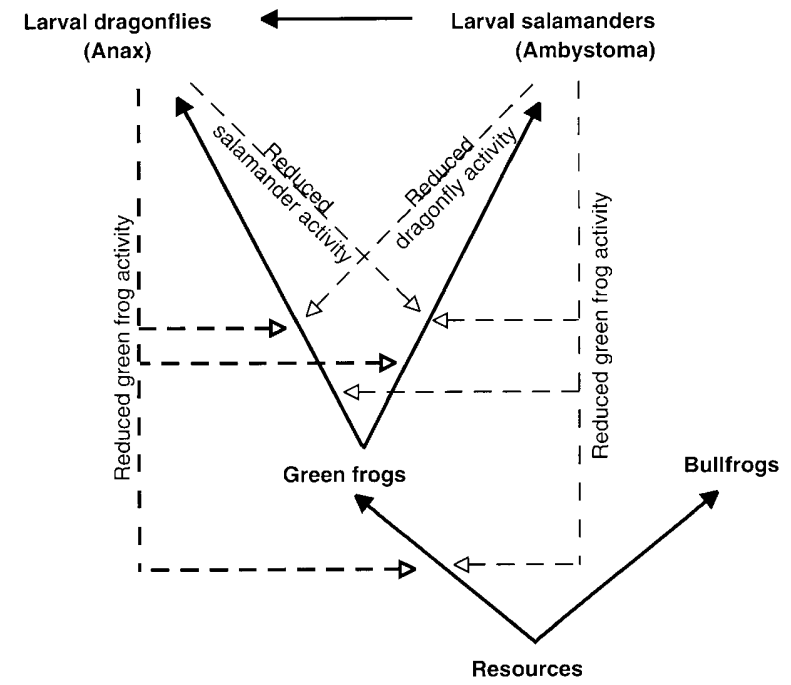

Fig. 1 An aquatic food web of predators, prey, and resources used in the mesocosm experiment. Potential density-mediated effects are indicated by solid lines (arrows pointing to the consumer). Potential trait-mediated effects are indicated by dashed lines, demonstrating how one species can potentially alter the traits of another species and thereby alter the per-capita interactions of the latter. Thicker lines indicate those effects that proved to be important at the end of the experiment

lethal Ambystoma on green frogs, but adding caged Ambystoma have no effect on the predation rate of lethal Anax on green frogs; (4) because only Anax reduces green frog activity, caged Anax should reduce green frog growth, but caged Ambystoma should have no effect; (5) any reductions in green frog resource acquisition (either through density- or trait-mediated effects) should have a positive effect on bullfrog growth (through their shared resource); and (6) Anax should kill Ambystoma, but Ambystoma should not kill Anax.

\section{Materials and methods}

\section{Animal collection and rearing}

All animals used in the experiments were collected on the E.S. George Reserve in southeastern Michigan. Green frogs were collected as a mixture of ten egg masses from several nearby ponds whereas large second- and third-year bullfrog tadpoles (which are typically two orders of magnitude more massive) were seined from a single nearby pond. We reared all tadpoles outdoors in $300-1$ wading pools containing aged well water under $60 \%$ shade cloth and fed them rabbit chow ad libitum until their use in the experiments. Predatory dragonfly larvae also were collected from the experimental ponds; they were held individually in 500-ml plastic cups and fed green frog tadpoles until used in the experiments. Ambystoma larvae were collected as eggs from two natural ponds in Livingston County in southeastern Michigan. The larvae were raised first in outdoor wading pools and then in individual 500-ml plastic cups in the lab; they were fed zooplankton and green frog tadpoles until used in the experiments.

\section{Laboratory experiments}

The laboratory experiments were designed to quantify predatorinduced behavioral responses. Behavioral responses of green frog tadpoles to Anax and Ambystoma were documented in an earlier study (Relyea 2001a) and these data were used develop our predictions in the mesocosm experiment. In that experiment, groups of ten newly hatched green frogs (mean mass $=20 \mathrm{mg}$ ) were reared in plastic tubs containing 71 of aged well water. Tubs were placed on shelves in two spatial blocks and each tub was equipped with a predator cage constructed of two wooden slats that suspended a 1-mm-mesh bag. Each cage contained either no predator, a single caged Anax, or a single caged larval Ambystoma. All treatments were replicated 4 times in a randomized block design. Predators and prey were fed 3 times per week; prey were fed at a per-capita rate of $6 \%$ of mean mass and predators were fed 3-10 green frog tadpoles (total mass of approximately $100 \mathrm{mg}$ ). The experiment lasted for 35 days; every 7 days the tadpoles were weighed and the tub water was changed. Activity was measured using 37 scan samples (Altmann 1974) to count the number of active (moving) tadpoles throughout the day. Activity level was quantified for each tub as the mean proportion of active tadpoles across the 37 observations.

We also conducted new (previously unpublished) laboratory experiments to quantify the behavioral responses of bullfrog tadpoles to each of the predators, and the behavioral responses of the two predator species to each other. In this case, experimental units were 40-1 aquaria filled with aged well water, arranged in a completely randomized design along shelves in the laboratory. Fluorescent lighting above the aquaria operated on a 14:10 light:dark cycle. Each aquarium contained a predator cage consisting of a plastic cup with a small piece of polystyrene for flotation and a screen covering on one end.

For the bullfrog experiment, we placed five tadpoles (mean individual mass $=11.22 \mathrm{~g}$ ) in each aquarium on 23 June 1998 and randomly assigned one of three treatments: an empty cage, one caged Anax, or one caged Ambystoma. Each treatment was replicated 5 times. Each caged predator was fed 15 green frog tadpoles (a total mass of approximately $150 \mathrm{mg}$ ), and the animals were left overnight to acclimate to the experimental conditions. It is likely that bullfrog tadpoles respond the same way to predators consuming green frog tadpoles as they would to predators fed bullfrog tadpoles; previous work has shown that ranid tadpoles cannot discriminate between predators fed conspecific tadpoles versus congeneric tadpoles (Relyea and Werner 2000). On 24 June 1998, we observed behavior in each aquarium using 40 scan samples to count the number of active tadpoles throughout the day. Activity level was quantified for each aquarium as the mean proportion of active tadpoles across the 40 observations.

The experiments testing the response of Anax to Ambystoma, and vice versa, followed the same protocol, with three exceptions. First, only one individual was placed in each aquarium because both Anax and Ambystoma larvae can be cannibalistic. Second, in the Anax experiment, each aquarium contained three wooden dowels so that Anax could perch as they often do in natural habitats. Third, we observed each of the aquaria in the Anax and Ambystoma experiments using 40 scan samples on 24 June and an additional 20 scan samples on 25 June 1998, after feeding the target individuals a mixture of zooplankton collected from a nearby pond. We performed more observations on the predators than the prey because we expected that behavioral data based on one focal individual would be more variable than our data from the tadpole experiments where we observed groups of 5-10 individuals. The proportion of activity was calculated by dividing the number of times each individual was active by the 60 observations taken. Ambystoma individuals used in this experiment weighed an average of $990 \mathrm{mg}$; Anax individuals were not measured but were all in the penultimate instar (typically $4-5 \mathrm{~cm}$ ) and similar in size to the Ambystoma larvae. In these observations of predator behavior, it is important to note that we were testing how each predator responded to the other predator eating green frogs, not how each predator responded to the other predator eating predators. This is the more appropriate design because the mesocosm experiment focused on how interspecific interactions change when predators eat green frogs.

For each of the laboratory experiments, we analyzed mean activity using an analysis of variance (ANOVA), and used Fisher's test to conduct mean comparisons. For the green frog experiment, 
we arcsine-square-root transformed the data to meet the assumptions of normality and homoscedasticity of errors. The behavioral data for the bullfrog experiment and the predator experiment did not depart seriously from the assumptions of normality and homoscedasticity as assessed using Lilliefors' and Bartlett's tests, respectively. Thus, we did not transform the data. For experiments containing randomized block designs, the block effects were never significant and were dropped from the analyses.

\section{Mesocosm experiment}

To quantify the density- and trait-mediated effects of the two predator species on tadpole morphology, growth, and survivorship, we reared green frog and bullfrog tadpoles together under a $3 \times 3$ completely randomized factorial design: three Anax treatments (no Anax, two nonlethal (caged) Anax, or two lethal Anax) crossed with three Ambystoma treatments (no Ambystoma, two nonlethal Ambystoma, or two lethal Ambystoma). The entire design was replicated five times for a total of 45 experimental units. Additionally, we set up five extra replicate tanks assigned to the lethal Anax/lethal Ambystoma treatment for destructive sampling during the experiment. These tanks helped us assess the rate of predation so that we could stop the experiment before all of the green frog tadpoles were killed. After sampling three of the five tanks, we decided to terminate the experiment, leaving two replicates that we included in the statistical analysis (for a total of 47 experimental units).

Experimental units were 1,000-1 cattle watering tanks which we filled with well water on 20 June 1998. At that time, we also added to each tank $300 \mathrm{~g}$ of Quercus leaves, $25 \mathrm{~g}$ of rabbit chow, and a $250 \mathrm{ml}$ aliquot of phytoplankton from an experimental pond. The leaves added structure to the environment and provided a surface for periphyton growth whereas the rabbit chow and aliquot of pond water were added to stimulate the growth of bacteria and algae. On the following day, we added a $125 \mathrm{ml}$ aliquot of zooplankton (collected from a natural pond) to each tank. These additions were intended to make the cattle tanks contain many of the components of natural ponds. We covered the tanks with lids made from $60 \%$ shade cloth to prevent unwanted insects and amphibians from colonizing the experiment.

We equipped each tank with four predator cages. Each cage was a piece of slotted sewer drain pipe $(10 \times 11 \mathrm{~cm})$ with $2 \mathrm{~mm}$ fiberglass screening over each end, so that predators were not lethal to tadpoles in the tank but chemical cues could be produced by the predators and diffuse out into the tank. We placed a small piece of polystyrene in each cage for flotation. Each cage was either empty or contained a single predator individual, depending on the treatment. Tanks contained four empty cages (four of the treatments), two empty and two occupied cages (four of the treatments), or four occupied cages (one of the treatments).

On 27 June 1998, we added 200 green frogs $\left(113 / \mathrm{m}^{2}\right.$, mean individual mass $=20 \mathrm{mg})$ and 5 bullfrogs $\left(3 / \mathrm{m}^{2}\right.$, mean individual mass $=10.71 \mathrm{~g}$ ) to each tank. Based on five years of survey data, first-year green frog tadpoles can achieve pond-wide densities of up to $87 / \mathrm{m}^{2}$ and microhabitat densities of up to $670 / \mathrm{m}^{2}$; secondyear bullfrog tadpoles can achieve pond-wide densities of up to $1.7 / \mathrm{m}^{2}$ (Werner et al., unpublished data). Thus our initial densities were relatively high, but we anticipated that predation would quickly reduce green frog densities to more natural levels. Predators were added to the tanks on 27 June. The lethal predators were caged for the first 2 days of the experiment (27-29 June) to give the tadpoles an opportunity to detect the predators' presence before any direct predation was allowed. Caged predators were fed green frogs 3 times per week throughout the experiment. At each feeding, a predator was given 2-3 tadpoles (mean total mass $=370 \mathrm{mg}$ ). Empty cages were picked up and gently dropped back into the tanks to control for tank disturbance. We randomly assigned predators to the lethal predator treatments but did not note their initial size. Throughout the experiment, all caged predators that died or began metamorphosis were replaced. Only one bullfrog tadpole died during the course of the experiment and the death was not predator-related. The dead bullfrog was replaced with a similar-sized bullfrog tadpole to maintain a constant competitor density.

The destructively sampled tanks indicated that the predators had killed nearly all of the green frogs after 3 weeks, so we terminated the experiment. During this time, we attempted to quantify tadpole activity in the tanks. However, our attempts were unsuccessful because water clarity differed among treatments (previous experiments have shown good agreement between activity observed in the laboratory and activity observed in pond mesocosms; Peacor and Werner1997; Relyea 2002b). On 17-18 July 1998, we drained the tanks, sorted through the leaf litter, and quantified the survival and growth (mean final mass - mean initial mass) of the tadpoles and the survival and final size of the predators (standard length of Anax, mass of Ambystoma). A random sample of up to ten green frogs from each tank was preserved in $10 \%$ formalin for subsequent morphological analysis. To measure green frog morphology, we used the BioScan Optimas digitizing program which allowed us to trace seven linear measures of tadpole shape from an image captured on a video monitor. We measured five traits from a lateral view of each tadpole (tail length, tail depth, tail muscle depth, body length, body width) and two traits from a dorsal view [tail muscle width, body width; see Relyea (2000) for a photograph of tadpole dimensions]. Each tadpole was weighed after being measured.

\section{Statistical analyses of the mesocosm experiment}

Our statistical analyses of the mesocosm experiment required the omission of three tanks. In two tanks that contained lethal Ambystoma, only one Ambystoma survived; this mortality was not due to predation by lethal Anax (treatments: caged Anax plus lethal Ambystoma, no Anax plus lethal Ambystoma). In one tank that contained lethal Anax, only one Anax survived; this mortality was not due to predation by lethal Ambystoma (treatment: caged Ambystoma plus lethal Anax). For all of the analyses, we used Lilliefors' and Bartlett's tests to examine whether there were any serious departures from normality and homoscedasticity, respectively. All pairwise mean comparisons were conducted using Fisher's test.

We began by analyzing the effects of the two predators on each other. The effects of the Ambystoma treatments on lethal Anax survival and Anax body length were analyzed with a multivariate analysis of variance (MANOVA). The effect of the Anax treatments on lethal Ambystoma survival was analyzed with the nonparametric Kruskal-Wallis test because the survival data were heteroscedastic and were not correctable by transformation. We used an ANOVA to test the effect of Anax treatment on Ambystoma mass.

We then conducted MANOVAs to analyze the effects of the Anax and Ambystoma treatments on green frog growth, survival, and morphology. The first MANOVA analyzed the effects on growth and survivorship. After survivorship data were arcsinesquare-root transformed, there were no serious departures from normality or homoscedasticity. The second MANOVA analyzed the effects of the Anax and Ambystoma treatments on the relative morphology of green frogs. To quantify relative morphology, we first had to generate size-independent morphological measurements. We did this by first regressing log-transformed morphological measurements against log-transformed mass (transformed to correct for nonlinearities) for all individuals and saving the residuals (which represented size-independent morphology; Van Buskirk and Relyea 1998 ; Relyea 2000). The residuals from this regression were averaged by tank, and these mean residuals were entered into a MANOVA with Anax and Ambystoma treatments as the fixed factors. The nonsignificant Anax-by-Ambystoma interaction term was removed to increase the power of the analysis.

Larval bullfrogs in the experiment achieved a maximum mass at Gosner stage 41 (Gosner 1960) and then declined as individuals stopped feeding and began to undergo metamorphosis. For our purposes, we wanted to know how much biomass the bullfrog tadpoles had accumulated prior to initiating metamorphosis (i.e. peak bullfrog mass). Therefore, we first regressed Gosner stage 


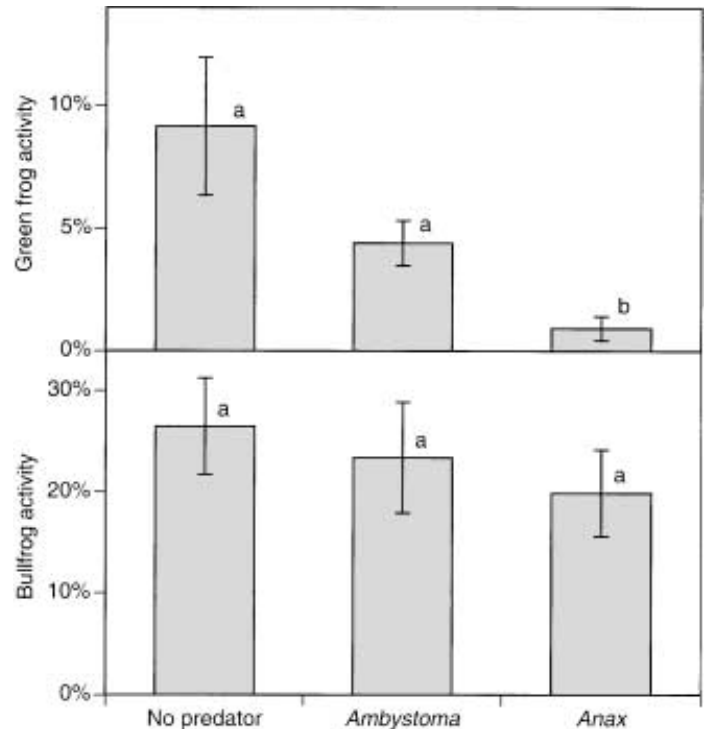

Fig. 2 The activity of first-year green frogs (upper panel) and second-year bullfrogs (lower panel) when reared under laboratory conditions with either no predators, caged Ambystoma, or caged Anax (means $\pm 1 \mathrm{SE}$ ). Means with common superscripts are not significantly different $(P>0.05)$

against mass (for all individuals of stage $\geq 41$ ) to quantify mass loss during metamorphosis. Using the resulting regression coefficient and knowing the Gosner stage of each bullfrog, one can estimate the peak mass for each bullfrog that had metamorphosed (Werner and Anholt 1996). We used these estimated masses, combined with untransformed masses of individuals < 41 Gosner stage, in a MANOVA to test for the effects of Anax and Ambystoma treatments on bullfrog growth (mean final mass - mean initial mass). Finally, to examine whether changes in bullfrog growth were due to competition between bullfrogs and green frogs, we regressed bullfrog growth against total green frog biomass (number of green frog survivors $\times$ mean green frog growth) across all tanks. A negative relationship between green frog growth and bullfrog growth would be evidence of competition, particularly in light of past mesocosm experiments that have demonstrated competition between these two species at similar densities (Werner and Anholt 1996; Peacor and Werner 1997)

\section{Results}

\section{Laboratory experiments}

The laboratory experiments documented how the two prey species behaviorally responded to the two predators and how the two predators behaviorally responded to each other. First-year green frogs responded to the predators by reducing their activity $\left(F_{2,9}=8.89, P=0.007\right.$; Fig. 2). Relative to the control, the reduction was not sig-

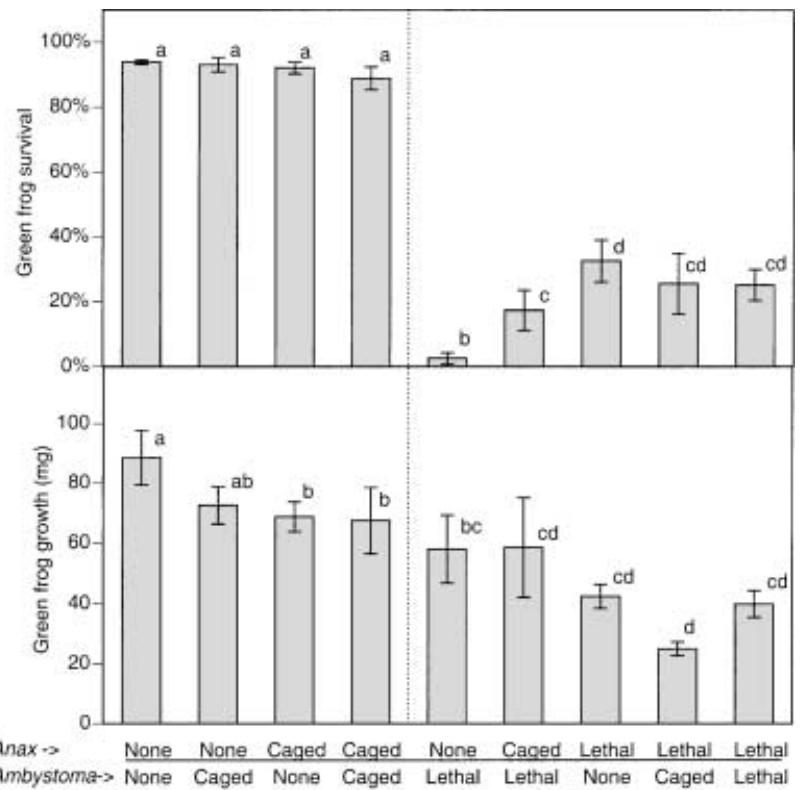

Fig. 3 The effect of Anax and Ambystoma predators (either absent, caged, or lethal) on larval green frog growth and survivorship (means $\pm 1 \mathrm{SE}$ ). Means with common superscripts are not different $(P>0.09)$

nificant $(P=0.118)$ in the presence of Ambystoma but it was significant in the presence of Anax $(P=0.002)$. Activity in the presence of caged Anax was lower than in the presence of caged Ambystoma treatment $(P=0.036)$. In contrast, second-year bullfrogs did not alter their activity with either predator $\left(F_{212}=0.461, P=0.641\right)$. In the experiments that tested how the predators responded to each other, we found that Anax did not alter their activity in the presence of Ambystoma eating green frogs $\left(F_{1,8}=2.30, P=0.168\right)$ and Ambystoma did not alter their activity in the presence of Anax eating green frogs $\left(F_{1,8}=0.01, P=0.914\right)$.

\section{Mesocosm experiment}

\section{Predators}

In the mesocosm experiment, the predators affected each other's survivorship, but not each other's final size (unless mentioned otherwise, all mean comparisons are given relative to the control treatment). Anax experienced no differences in survivorship or size among the three Ambystoma treatments (Wilks' $F_{4,26}=1.07, P=0.393$ ). In contrast, Ambystoma survivorship was high with no Anax and caged Anax, but reduced to zero with lethal
Table 1 MANOVA results from the analysis examining the effect of Anax (absent, caged, and lethal) and the effect of Ambystoma (absent, caged, and lethal) on larval green frog growth and survival in the pond mesocosm experiment

\begin{tabular}{llll}
\hline Source & Multivariate & $\begin{array}{l}\text { Univariate } \\
\text { Survivorship }\end{array}$ & $\begin{array}{l}\text { Univariate } \\
\text { Growth rate }\end{array}$ \\
\hline Anax & $F_{4,64}=20.0, P<0.001$ & $F_{2,33}=41.8, P<0.001$ & $F_{2,33}=20.2, P<0.001$ \\
Ambystoma & $\mathrm{F}_{4,64}=32.0, \mathrm{P}<0.001$ & $F_{2,33}=118.3, P<0.001$ & $F_{2,33}=5.2, P=0.011$ \\
Anax $\times$ Ambystoma & $F_{8,64}=11.6, P<0.001$ & $F_{4,35}=37.8, P<0.001$ & $F_{4,35}=2.2, P=0.089$ \\
\hline
\end{tabular}


Table 2 Multivariate MANOVA results from the analysis examining the effect of Anax (absent, caged, and lethal) and Ambystoma (absent, caged, and lethal) on larval green frog morphology in the pond mesocosm experiment

\begin{tabular}{llll}
\hline Source & $d f$ & Wilks' $F$ & $P$ \\
\hline Anax & 14,62 & 1.98 & 0.035 \\
Ambystoma & 14,62 & 0.96 & 0.499 \\
\hline
\end{tabular}

Table 3 Univariate MANOVA results from the analysis examining the effect of Anax (absent, caged, and lethal) and Ambystoma (absent, caged, and lethal) on larval green frog morphology in the pond mesocosm experiment

\begin{tabular}{|c|c|c|c|c|c|}
\hline \multirow[t]{2}{*}{ Source } & \multicolumn{5}{|c|}{$F$ statistic (upper value) and $P$-value (lower value) } \\
\hline & $\begin{array}{l}\text { Body Body } \\
\text { depth length }\end{array}$ & $\begin{array}{ll}\text { Body } & \text { Tail } \\
\text { width } & \text { depth }\end{array}$ & $\begin{array}{l}\text { Tail } \\
\text { length }\end{array}$ & $\begin{array}{l}\text { Muscle } \\
\text { depth }\end{array}$ & $\begin{array}{l}\text { Muscle } \\
\text { width }\end{array}$ \\
\hline Anax & $\begin{array}{rr}2,37 & (0.07) \\
0.935 & 0.012)\end{array}$ & $\begin{array}{rr}(0.03) & (0.58) \\
0.968 & 0.566\end{array}$ & $\begin{array}{l}(9.49) \\
<0.001\end{array}$ & $\begin{array}{r}(1.23) \\
0.303\end{array}$ & $\begin{array}{r}(1.65) \\
0.206\end{array}$ \\
\hline Ambyston & $\begin{array}{rrr}a 2,37 & (1.69) & (0.424 \\
0.199 & 0.657\end{array}$ & $\begin{array}{rr}(2.86) & (0.60) \\
0.070 & 0.555\end{array}$ & $\begin{array}{r}(0.67) \\
0.519\end{array}$ & $\begin{array}{l}(0.35) \\
0.706\end{array}$ & $\begin{array}{r}(1.25) \\
0.299\end{array}$ \\
\hline
\end{tabular}

Anax (Kruskal Wallis test statistic $=14.1, P=0.001$ ). Ambystoma mass was unaffected by the presence of caged $\operatorname{Anax}\left(F_{1,8}=2.42, P=0.159\right)$.

\section{Green frogs}

The mesocosm treatments had a significant multivariate effect on green frog growth and survival (Table 1, Fig. 3). Relative to the control, green frog survival was not affected by caged Ambystoma $(P=0.949)$, caged Anax $(P=0.801)$, or caged Ambystoma plus caged Anax $(P=0.444)$. However, green frog survivorship was greatly reduced by lethal Ambystoma, lethal Anax, and lethal Ambystoma plus lethal Anax $(P<0.001)$. Fewer green frogs survived with lethal Ambystoma than with lethal Anax or lethal Ambystoma plus lethal Anax $(P=0.001)$; the latter two treatments did not differ $(P=0.243)$. When lethal Ambystoma were present, adding caged Anax increased green frog survivorship $(P=0.020)$. However, when lethal Anax were present, adding caged Ambystoma did not affect green frog survivorship $(P=0.314)$.

The predator treatments also affected green frog growth (Table 1, Fig. 3). Relative to the control, green frog growth was not reduced with caged Ambystoma $(P=0.173)$ but tended to be reduced with caged Anax $(P=0.094)$ and caged Ambystoma plus caged Anax $(P=0.075)$. Lethal Ambystoma, lethal Anax $(P<0.02)$, and lethal Ambystoma plus Anax all reduced green frog growth $(P<0.02)$. When lethal Ambystoma were present, adding caged Anax did not further reduce green frog growth $(P=0.965)$; when lethal Anax were present, adding caged Ambystoma did not further reduce green frog growth $(P=0.162)$.

In the analysis of green frog morphology, we found that Anax affected the morphology of green frogs but Ambystoma did not (Tables 2, 3, Fig. 4). Both tail length

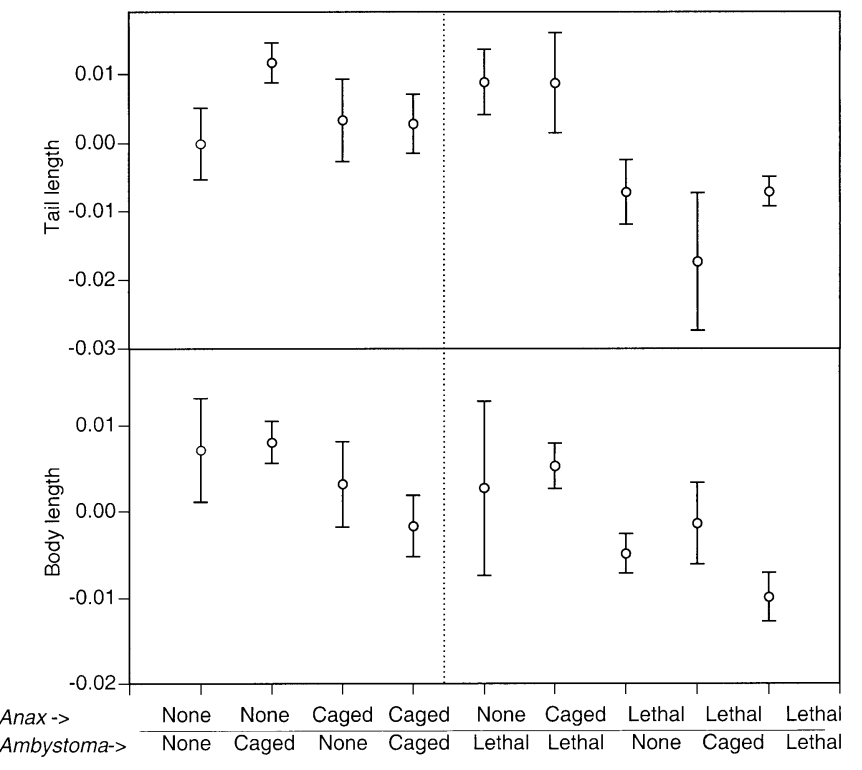

Fig. 4 The relative tail length and body length (means \pm 1 SE) of larval green frogs reared with Anax (NA no Anax, $C A$ caged Anax, LA lethal Anax) and Ambystoma (NT no Ambystoma, CT caged Ambystoma, LT lethal Ambystoma). Differences in overall size were removed prior to analysis by regressing the dimensions against mass and saving the residuals

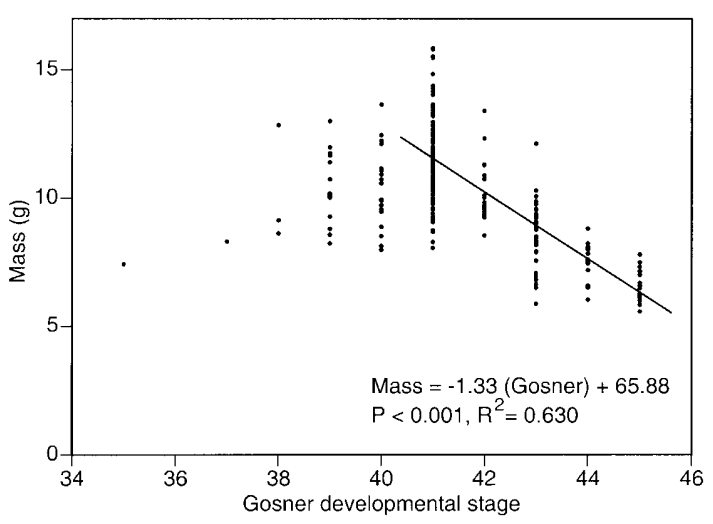

Fig. 5 The relationship between developmental stage and mass of larval bullfrogs. After Gosner (1960) stage 41, mass significantly declined as the tadpoles underwent metamorphosis $\left(R^{2}=0.630\right.$, $\left.F_{1,196}=333.1, P<0.001\right)$. The line represents a linear regression across stages $41-45$

and body length changed in the presence of Anax. Green frogs that survived lethal Anax had shorter tails $(P<0.003)$ and shorter bodies $(P=0.068$ and $P=0.003$, respectively) than green frogs reared with caged Anax or no Anax.

\section{Bullfrogs}

Bullfrog growth (developmentally adjusted) differed among treatments. Bullfrog mass achieved a maximum at Gosner stage 41 (Gosner 1960) and then declined as the animals began to metamorphose (Fig. 5). The linear 


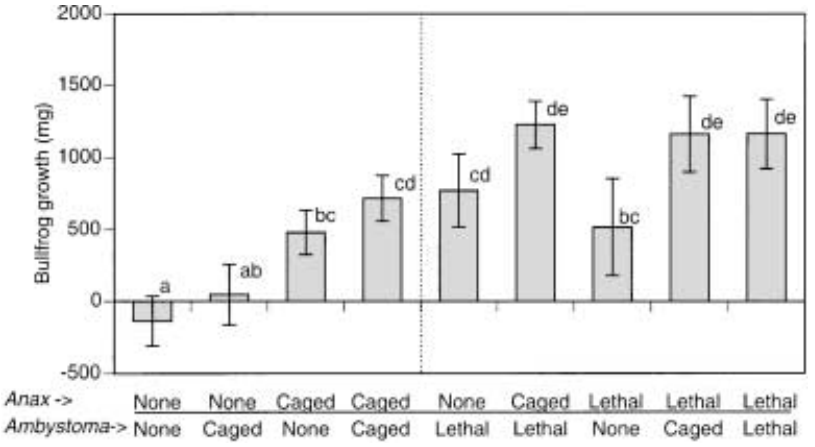

Fig. 6 Mass of larval bullfrogs raised under different predator treatments. Peak mass was back-calculated for those bullfrogs that had achieved a Gosner (1960) developmental stage $>41$ based on the linear relationship displayed in Fig. 5. Data are means \pm 1 SE. Means with common superscripts are not significantly different $(P>0.07)$

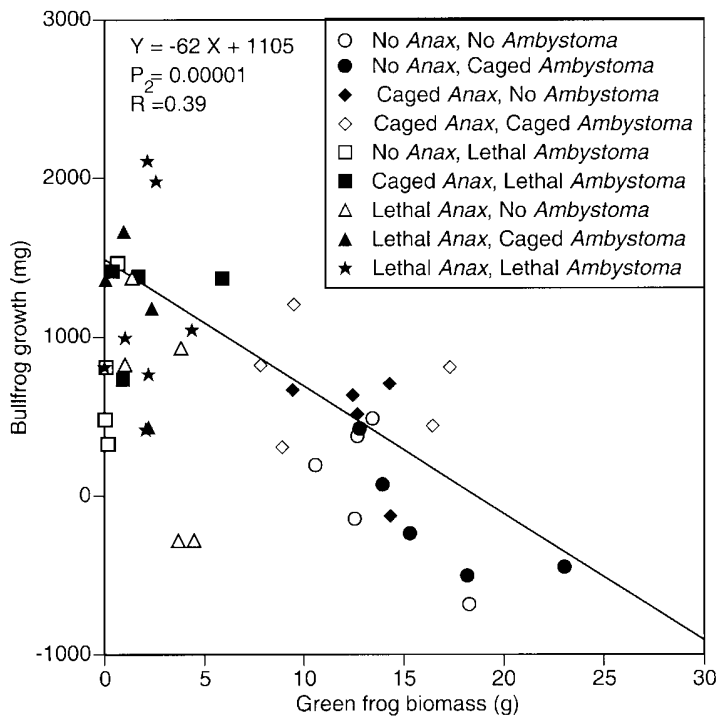

Fig. 7 The relationship between the total biomass of green frogs (surviving green frogs $\times$ mean green frog mass) and bullfrog growth in the mesocosm experiment. Each data point represents one experimental unit. The regression line is a single regression fit through all of the data points

regression of developmental stage against mass (for all individuals of stage $=41$ ) produced a significant negative relationship that described mass loss during metamorphosis $\left(R^{2}=0.630, F_{1,196}=333.1, P<0.001\right)$ and we used this relationship to back-calculate the peak mass of individual bullfrogs that were developed beyond stage 41 .

Using these back-calculated bullfrog masses, we found a significant effect of Ambystoma $\left(F_{2,35}=8.2\right.$, $P=0.001)$ and Anax $\left(F_{2,35}=8.0, P=0.001\right)$ on bullfrog growth, but no Anax-by-Ambystoma interaction $\left(F_{4,35}=0.7, P=0.627\right.$; Fig. 6). Bullfrog growth was unaffected by caged Ambystoma $(P=0.571)$, but tended to increase with caged Anax $(P=0.064)$. Adding lethal predators, either alone or in combination, also increased bullfrog growth. Adding caged Anax to tanks with lethal Ambystoma did not significantly increase bullfrog growth
( $P=0.215$ ), but adding caged Ambystoma to tanks with lethal Anax tended to increase bullfrog growth $(P=0.068)$. When we examined whether the above changes in bullfrog growth were due to competition between bullfrogs and green frogs, we found that bullfrog growth linearly increased as green frog biomass declined ( $P=0.00001, F_{1.42}=26.5, R^{2}=0.39$; Fig. 7$)$, with bullfrogs achieving maximal growth in treatments containing lethal predators.

\section{Discussion}

In our relatively simple five-component community, we observed a wide variety of direct and indirect links among species when we manipulated the presence and absence of caged and lethal predators. These links included direct predation, exploitative competition, interference competition in the form of intraguild predation, trait-mediated effects on interspecific competition, and trait-mediated effects on predation. Despite this complexity, we could qualitatively predict the direct and indirect effects of predators in the mesocosm experiment, either singly or in combination, based on our previous laboratory tests of how the predators affected the densities and traits of each other and their prey. We begin by discussing the density effects observed in our system, and then we discuss the trait-mediated effects.

The density effects involved predation by Anax on Ambystoma, predation by Anax and Ambystoma on green frogs, and herbivory by green frogs and bullfrogs on the periphyton resources (Fig. 8). Predation between the two predators was asymmetric. The predation by Anax on Ambystoma was not surprising given the wide range of prey that Anax can kill; Anax can be a voracious predator on $300 \mathrm{mg}$ larval Ambystoma and $500 \mathrm{mg}$ larval anurans (K. L. Yurewicz, personal observations; Eklöv and Werner 2000). Intraguild predation probably occurred very early in the experiment because green frogs reared with lethal Anax plus lethal Ambystoma did not differ in their survival or growth from green frogs reared with lethal Anax alone. In contrast, there was no predation by Ambystoma on Anax; this was likely due to a gape limitation of Ambystoma (K. L. Yurewicz, personal observations).

Relative predation rates of lethal Ambystoma and lethal Anax on green frogs and bullfrogs in the mesocosm experiment were consistent with earlier experiments. Second-year bullfrogs were simply too massive to be successively attacked by either predator; thus, there was no predation on bullfrogs. In contrast, recently hatched green frog tadpoles were highly vulnerable to predation. Past experiments in the laboratory have shown that predation by lethal Ambystoma is higher than predation by lethal Anax (Relyea 2001b) and we observed the same result in the mesocosm experiment. These results are likely due to trait differences between the two predators, including differences in hunting behavior (ambush-hunting Anax versus search-hunting Ambystoma) and prey 
handling time (faster for Ambystoma than Anax; Relyea 2001b). Because of these differences in predation risk, one might expect that green frogs would decrease their activity more in the presence of Ambystoma than Anax. However, recent work on anti-predator responses of anurans has demonstrated that anurans can use a suite of defensive responses and the magnitude of any single response frequently does not correlate with predation risk (Relyea 2001b). Differences in predation rate by different predators appear to be the norm in a variety of taxa (Kohler and McPeek 1989; Wissinger and McGrady 1993; Harris 1995; Kurzava and Morin 1998).

Direct consumer links also existed between each tadpole species and their periphyton prey. Reductions in green frog biomass were strongly associated with increases in bullfrog growth, suggesting that the two species were sharing a limited resource (i.e. periphyton). These two species commonly compete under experimental conditions (Werner 1991; Werner and Anholt 1996; Peacor and Werner 1997; Relyea and Werner 1999). While the growth of bullfrogs and green frogs were apparently connected through their shared resource (a densitymediated effect), the growth of both species was additionally impacted by trait-mediated effects (see below).

There were a number of trait-mediated effects in our experimental food web. While the predation rates by lethal Anax or Ambystoma alone were qualitatively consistent with past predation experiments in the laboratory (Relyea 2001b), the predation rates could be altered in the caged presence of a second predator. That is, the percapita interaction rate between the predators and prey depended on the ecological matrix in which the predation took place. For example, when Ambystoma was foraging on green frog tadpoles, few green frog tadpoles survived; when Ambystoma was foraging on green frog tadpoles and Anax were in the area producing chemical cues (i.e. caged Anax), green frog survival increased seven-fold. This relatively large increase in green frog survival occurred because green frog tadpoles detected the Anax cues and reduced their activity level (see Laboratory experiment) to lower their risk of predation (Gerritsen and Strickler 1977; Skelly 1992; Werner and Anholt 1993; Relyea 2001a). In contrast, when Anax was foraging on green frog tadpoles, green frog survival was not affected by Ambystoma chemical cues (i.e. caged Ambystoma). This lack of a survival difference occurred because Ambystoma did not reduce the activity of green frog tadpoles (see Laboratory experiment). Of course, these conclusions are based on the premise that the behavioral changes observed in the laboratory were also occurring in the mesocosms, a pattern that is supported by a number of other anuran studies (Peacor and Werner 1997; Relyea and Werner 1999; Relyea 2002b). From the laboratory experiment, we can conclude that the altered predation rates on green frogs were not due to predators affecting each other's activity (although, other traits not measured could have changed). However, past studies have shown that combined predators can have non-additive effects on prey survival either by altering prey behavior or by altering each other's behavior (Soluk and Collins 1988; Soluk 1993; Wissinger and McGrady 1993; Peacor and Werner 1997; Soluk and Richardson 1997; Levri 1998). In summary, trait-mediated effects from addition of predators can alter per-capita predation rates, and these alterations can be predicted from a knowledge of trait plasticity and trait function.

Trait-mediated effects also altered tadpole growth in directions that were qualitatively predictable. In the laboratory, green frog activity was significantly reduced with caged Anax $(P=0.01)$ but not with caged Ambystoma $(P=0.12)$. Reducing activity typically reduces resource consumption in tadpoles as well as many other taxa (Lima and Dill 1990; Werner and Anholt 1996; Kats and Dill 1998; Relyea and Werner 1999). In the mesocosms, green frog tadpoles exhibited marginally significant growth reduction in the presence of caged Anax $(P=0.09)$, but nonsignificant growth reduction in the presence of Ambystoma ( $P=0.17)$. Thus, Anax caused a trait-mediated effect by altering the per-capita interaction rate between green frog tadpoles and their resources but Ambystoma did not. This type of predator-induced reduction in prey growth is well supported in this and other experimental systems (Werner et al. 1983; Skelly 1994; Beckerman et al. 1997; Turner 1997; Relyea and Werner 1999; Relyea 2000). The effect of caged Anax plus caged Ambystoma on growth was always similar to caged Anax alone, suggesting that green frog activity with both caged predators may have been similar to green frog activity with caged Anax alone (we did not collect behavioral data with combined predators). This hypothesis is well supported in a recent experiment that examined a large number of predator combinations; in $90 \%$ of comparisons, pairs of predators induced the same trait state as the single predator that induced the more extreme trait state (Relyea, unpublished data).

The changes in green frog survival and growth caused by the simultaneous presence of multiple predators should have caused a feedback affecting the growth of the lethal predators. That is, if the addition of a second, caged predator altered predation rates of the first predator, this reduced consumption rate should have reduced the growth of the first predator. When Anax was lethal, the addition of caged Ambystoma did not alter Anax's consumption of tadpoles; as expected there was no difference in the final size of lethal Anax between the two treatments. In contrast, when Ambystoma was lethal, the addition of caged Anax significantly reduced Ambystoma's consumption of larval green frogs by $15 \%$ and reduced Ambystoma's growth by $20 \%$. Because the reduced growth was not significant $(P=0.158)$, we must conclude that the expected reduction in Ambystoma mass did not occur. Based on the laboratory study, it is unlikely that these results were influenced by predators altering each other's behavior; Anax activity was unaffected by the presence of caged Ambystoma and Ambystoma activity was unaffected by the presence of caged Anax.

The changes in bullfrog growth were another traitmediated effect. The predators reduced the activity of 
green frog tadpoles, less active green frog tadpoles fed less and grew less (presumably leaving more resources uneaten), and bullfrogs consumed the increased resources (as evidenced by their higher growth). Thus, just as one would predict from the laboratory experiments, caged Anax indirectly caused an increase in bullfrog growth but caged Ambystoma did not. It was the change in green frog traits, and not a change in green frog density (which did not differ among caged Anax and caged Ambystoma treatments), that accounted for the change in bullfrog growth. This result has been shown in previous anuran experiments (Werner and Anholt 1996; Peacor and Werner 1997, 2000). As mentioned above, when the predators were lethal, there was little change in green frog biomass and, as a result, little change in bullfrog growth.

Predators can affect not only the behavior of their prey but also the morphology of their prey. Predatorinduced changes in morphology can be substantial (Havel 1987 ; Tollrian and Harvell 1999) and can cause trait-mediated effects (Raimondi et al. 2000; Relyea 2000). Our study took an extensive approach that examined both activity and morphology and we found that predator cues (caged Anax and Ambystoma) altered green frog activity, but not green frog morphology. Thus, we can rule out the possibility that morphology was responsible for the trait-mediated effects observed in the mesocosm experiment. The lack of significant morphological changes by green frog tadpoles, in response to either predator, is in agreement with previous work on green frog tadpoles (Relyea 2001a). The only treatment that caused a difference in morphology was the lethal Anax treatment in which surviving green frogs exhibited shorter tails and longer bodies. These changes are most likely the result of several predatory processes including missed strikes that removed the tips of tails, the preferential killing of tadpoles that possessed relatively larger bodies (i.e. natural selection; Van Buskirk et al. 1997; Van Buskirk and Relyea 1998), and reduced competition due to predation (Relyea 2002a, b). Overall, the morphological data inform us that the trait-mediated effects were likely mediated through changes in green frog behavior and not through changes in green frog morphology.

\section{Conclusions}

In the beginning of this study, we began with numerous potential interactions and we experimentally determined which ones were important. In the end, we saw that lethal dragonflies were predators on both salamanders and green frogs while the salamanders were only predators on green frogs (Fig. 1). The dragonflies reduced the activity of the green frogs and this caused a decrease in green frog predation by salamanders, a decrease in resource acquisition by green frogs, and an increase in resource acquisition by bullfrogs. The salamanders had no significant effect on green frog activity, no effect on resource acquisition by green frogs, and no effect on resource acquisition by bullfrogs. All of these densityand trait-mediated interactions were qualitatively predictable from a knowledge of (1) per-capita interactions between species pairs, (2) the plasticity of traits in the presence of different species pairs, and (3) how changing traits alter per-capita interactions.

Predicting community structure from pairwise changes in species' density has proven to be a difficult endeavor (Vandermeer 1969; Wilbur and Fauth 1990; Billick and Case 1994). It is increasingly clear that our understanding of species interactions has been limited, in part, because we have not given proper attention to the plasticity of species traits and the impact of trait-mediated effects. It has been long known that trait plasticity is common (see reviews by Lima and Dill 1990; Travis 1994; Schlichting and Pigliucci 1998), but only recently has it become clear that trait plasticity is important beyond the individual; it can be vitally important to other species in the community (Wootton 1992, 1993; Beckerman et al. 1997; Peacor and Werner 1997; Raimondi et al. 2000; Turner et al. 2000; Relyea 2000). It is encouraging to find that when we identify relevant plastic traits and understand their function, we improve our ability to predict community changes. Obviously, most natural communities have many more taxa than the system we studied and this may mean that quantifying pairwise density- and trait-mediated interactions to predict community changes remains a prohibitively large task. It seems that continuing our buildup to larger and more complex communities is the path that lies ahead.

Acknowledgements We thank Dexter Bakery, Neil Kubica, and Keith Wittkopp for their hard work in assisting us in the experiments. Thanks also go to Ronald Nussbaum and Richard Alexander for providing access to the E.S. George Reserve. Jason Hoverman, Shannon McCauley, Andy Turner, Earl Werner, and Mara Zimmerman provided many helpful comments on the manuscript. This work was supported by University of Michigan research grants, Sigma Xi research grants, a University of Michigan Regents' Fellowship to K.L.Y., and NSF grant DEB-9701111 to R.A.R. Animal care was within institutional guidelines.

\section{References}

Abrams PA (1995) Implications of dynamically variable traits for identifying, classifying, and measuring direct and indirect effects in ecological communities. Am Nat 146:112-134

Adler FR, Morris WF (1994) A general test for interaction modification. Ecology 75:1552-1559

Adolph EF (1931) The size of the body and the size of the environment in the growth of tadpoles. Biol Bull 61:350-375

Altmann J (1974) Observational study of behavior: sampling methods. Behaviour 49:227-267

Beckerman AP, Uriarte M, Schmitz OJ (1997) Experimental evidence for a behavior-mediated trophic cascade in a terrestrial food chain. Proc Natl Acad Sci 94:10735-10738

Billick I, Case T (1994) Higher order interactions in ecological communities: what are they and how can they be detected? Ecology 75:1529-1543

Collins JP, Wilbur HM (1979) Breeding habits and habitats of the amphibians of the Edwin S. George Reserve, Michigan, with notes on the local distribution of fishes. Occas Pap Mus Zool Univ Mich No 686 
Dale JM, Freeman B, Kerekes J (1985) Acidity and associated water chemistry of amphibian habitats in Nova Scotia. Can J Zool 63:97-105

Eklöv P, Werner EE (2000) Multiple predator effects on sizedependent behavior and mortality of two species of anuran larvae. Oikos 88:250-258

Gerritsen J, Strickler JR (1977) Encounter probabilities, and the community structure in zooplankton: a mathematical model. J Fish Res Board Can 34:73-82

Gosner KL (1960) A simplified table for staging anuran embryos and larvae with notes on identification. Herpetologica 16: 183-190

Harris PM (1995) Are autecologically similar species also functionally similar? A test in pond communities. Ecology 76: $544-552$

Havel JE (1987) Predator-induced defenses: a review. In: Kerfoot WC and Sih A (eds) Predation: direct and indirect impacts on aquatic communities. New England University Press, Hanover, N.H. pp 263-278

Hews DK (1988) Alarm response in larval western toads, Bufo boreas: release of larval chemicals by a natural predator and its effect on predator capture efficiency. Anim Behav 36: $125-133$

Karban R, Baldwin IT (1997) Induced responses to herbivory. University of Chicago Press Chicago, Ill.

Kats LB, Dill LM (1998) The scent of death: chemosensory assessment of predation risk by prey animals. Ecoscience 5:361-394

Kats LB, Petranka JW, Sih A (1988) Antipredator defenses and the persistence of amphibian larvae with fishes. Ecology 69: $1865-1870$

Kohler SL, McPeek MA (1989) Predation risk and the foraging behavior of competing stream insects. Ecology 70:1811-1825

Kurzava LM, Morin PJ (1998) Tests of functional equivalence: complementary roles of salamanders and fish in community organization. Ecology 79:477-489

Lawler SP (1989) Behavioural responses to predators and predation risk in four species of larval anurans. Anim Behav 38: $1039-1047$

Levri EP (1998) The influence of non-host predators on parasiteinduced behavioral changes in a freshwater snail. Oikos 81: $531-537$

Lima SL, Dill LM (1990) Behavioral decisions made under the risk of predation: a review and prospectus. Can J Zool 68: 619-640

Martof, B (1956) Factors influencing size and composition of populations of Rana clamitans. Am Midl Nat 56:224-245

McCollum SA, Van Buskirk J (1996) Costs and benefits of a predator-induced polyphenism in the gray treefrog Hyla chrysoscelis. Evolution 50:583-593

McIntosh AR, Townsend CR (1996) Interactions between fish, grazing invertebrates and algae in a New Zealand stream: a trophic cascade mediated by fish-induced changes in grazer behavior? Oecologia 108:174-181

Morin PJ (1983) Predation, competition, and the composition of larval anuran guilds. Ecol Monogr 53:119-138

Peacor SD, Werner EE (1997) Trait-mediated indirect interactions in a simple aquatic food web. Ecology 78:1146-1156

Peacor SD, Werner EE (2000) Predator effects on an assemblage of consumers through induced changes in consumer foraging behavior. Ecology 81:1998-2010

Petranka JW, Kats LB, Sih A (1987) Predator-prey interactions among fish and larval amphibians: use of chemical cues to detect predatory fish. Anim Behav 35:420-425

Polis GA, Holt RD (1992) Intraguild predation: the dynamics of complex trophic interactions. Trends Evol Ecol 7:151-154

Polis GA, Myers CA, Holt RD (1989) The ecology and evolution of intraguild predation: potential competitors that eat each other. Annu Rev Ecol Syst 20: 297-330

Raimondi, PT; Forde, SE; Delph, LF; Lively, CM (2000) Processes structuring communities: evidence for trait-mediated indirect effects through induced polymorphisms. Oikos 91:353-361
Relyea RA (2000) Trait-mediated effects in larval anurans: reversing competitive outcomes with the threat of predation. Ecology $81: 2278-2289$

Relyea RA (2001a) Morphological and behavioral plasticity of larval anurans in response to different predators. Ecology $82: 523-540$

Relyea RA (2001b) The relationship between predation risk and antipredator responses in larval anurans. Ecology 82:541-554

Relyea RA (2002a) Competitor-induced plasticity in tadpoles: consequences, cues, and connections to predator-induced plasticity. Ecology (in press)

Relyea RA (2002b) The many faces of predation: how selection, induction, and thinning combine to alter prey phenotypes. Ecology (in press)

Relyea RA, Werner EE (1999) Quantifying the relation between predator-induced behavior and growth performance in larval anurans. Ecology 80:2117-2124

Relyea RA, Werner EE (2000) Morphological plasticity of four larval anurans distributed along an environmental gradient. Copeia 2000:178-190

Schlichting CD, Pigliucci M (1998) Phenotypic evolution: a reaction norm perspective. Sinauer, Sunderland, Mass.

Schmitz OJ (1998) Direct and indirect effects of predation and predation risk in old-field interaction webs. Am Nat 151: 327-342

Sih A, Englund G, Wooster D (1998) Emergent impacts of multiple predators on prey. Trends Evol Ecol 13:350-355

Skelly DK (1992) Field evidence for a cost of behavioral antipredator response in a larval amphibian. Ecology 73:704-708

Skelly DK (1994) Activity level and the susceptibility of anuran larvae to predation. Anim Behav 47:465-468

Skelly DK, Werner EE, Cortwright SA (1999) Long-term distributional dynamics of a Michigan amphibian assemblage. Ecology 80:2326-2337

Soluk DA (1993) Multiple predator effects: predicting combined functional response of stream fish and invertebrate predators. Ecology 74:219-225

Soluk DA, Collins NC (1988) Synergistic interactions between fish and stoneflies: facilitation and interference among stream predators. Oikos 52:94-100

Soluk DA, Richardson JS (1997) The role of stoneflies in enhancing growth of trout: a test of the importance of predator-predator facilitation within a stream community. Oikos 80:214-219

Tollrian R, Harvell D (1999) The ecology and evolution of inducible defenses. Princeton University Press, Princeton, N.J.

Travis J (1994) Evaluating the adaptive role of morphological plasticity. In: Wainwright PC, Reilly SM (eds) Ecological morphology. University of Chicago Press, Chicago, pp 99-122

Turner AM (1997) Contrasting short-term and long-term effects of predation risk on consumer habitat use and resources. Behav Ecol 8:120-125

Turner AM, Mittelbach GG (1990) Predator avoidance and community structure: interactions among piscivores, planktivores, and plankton. Ecology 71:2241-2254

Turner AM, Bernot RJ, Boes CM (2000) Chemical cues modify species interactions: The ecological consequences of predator avoidance by freshwater snails. Oikos 88:148-158

Van Buskirk J, Relyea RA (1998) Natural selection for phenotypic plasticity: predator-induced morphological responses in tadpoles. Biol J Linn Soc 65:301-328

Van Buskirk J, Yurewicz KL (1998) Effects of predators on prey growth rate: relative contributions of thinning and reduced activity. Oikos 82:20-28

Van Buskirk J, McCollum SA, Werner EE (1997) Natural selection for environmentally induced phenotypes in tadpoles. Evolution 52:1983-1992

Vandermeer JH (1969) The competitive structure of communities: an experimental approach with Protozoa. Ecology 50:362-371

Werner EE (1991) Nonlethal effects of a predator on competitive interactions between two anuran larvae. Ecology 72 : $1709-1720$ 
Werner EE (1992) Individual behavior and higher-order species interactions. Am Nat 140:P5-P32

Werner EE, Anholt BR (1993) Ecological consequences of the trade-off between growth and mortality rates mediated by foraging activity. Am Nat 142:242-272

Werner EE, Anholt BR (1996) Predator-induced behavioral indirect effects: consequences to competitive interactions in anuran larvae. Ecology 77:157-169

Werner EE, McPeek MA (1994) Direct and indirect effects of predators on two anuran species along an environmental gradient. Ecology 75:1368-1382

Werner EE, Gilliam JF, Hall DJ, Mittelbach GG (1983) An experimental test of the effects of predation risk on habitat use in fish. Ecology 64:1540-1548

Wilbur HM 1972 Competition, predation, and the structure of the Ambystoma-Rana sylvatica community. Ecology 53:3-21

Wilbur HM (1988) Interactions between growing predators and growing prey. In: Ebenman B, Persson L (eds) Size structured populations. Springer, Berlin Heidelberg New York, pp 157-172
Wilbur HM, Fauth JE (1990) Experimental aquatic food webs: interactions between two predators and two prey. Am Nat 135: 176-204

Wissinger S, McGrady J (1993) Intraguild predation and competition between larval dragonflies: direct and indirect effects on shared prey. Ecology 74:207-218

Wootton JT (1992) Indirect effects, prey susceptibility, and habitat selection: Impacts of birds on limpets and algae. Ecology 73:981-991

Wootton JT (1993) Indirect effects and habitat use in an intertidal community: interaction chains and interaction modifications. Am Nat 141:71-89

Wootton JT (1994) The nature and consequences of indirect effects in ecological communities. Annu Rev Ecol Syst 25: 443-466

Worthen WB, Moore JL (1991) Higher-order interaction and indirect effects: A resolution using laboratory Drosophila communities. Am Nat 138:1092-1104 